\title{
On iterative methods for bilevel equilibrium problems
}

\author{
Chanitnan Jaipranop ${ }^{1}$ and Satit Saejung ${ }^{2^{*}}$ (I)
}

\section{"Correspondence:}

saejung@kku.ac.th

2Department of Mathematics, Faculty of Science, Khon Kaen University, Khon Kaen, Thailand Full list of author information is available at the end of the article

\begin{abstract}
We use the notion of Halpern-type sequence recently introduced by the present authors to conclude two strong convergence theorems for solving the bilevel equilibrium problems proposed by Yuying et al. and some authors. Our result excludes some assumptions as were the cases in their results.
\end{abstract}

MSC: $47 \mathrm{H} 10 ; 47 \mathrm{H} 09 ; 54 \mathrm{H} 25$

Keywords: Bilevel equilibrium problems; Halpern sequence; Halpern-Korpelevič algorithm; Extragradient algorithm with line search technique

\section{Introduction}

Let $\mathcal{H}$ be a real Hilbert space. For a given bifunction $g: \mathcal{H} \times \mathcal{H} \rightarrow \mathbb{R}$, where $\mathbb{R}$ is the set of real numbers, the equilibrium problem associated with $g$ and a closed convex subset $C$ of $\mathcal{H}$ is described as follows:

Find $x^{*} \in C$ such that

$$
g\left(x^{*}, y\right) \geq 0 \quad \text { for all } y \in C \text {. }
$$

In particular, the solution set of the problem is given by $\mathrm{EP}(g, C)$. This problem plays an important role in various branches in pure and applied sciences such as fixed point theory, optimization, and game theory. The formulation was studied by Blum and Ottelli [3] in 1994 and has been studied by many authors. In this paper, we consider the bilevel equilibrium problem associated with two bifunctions $f$ and $g$ and a closed convex subset $C$ of $\mathcal{H}$ :

$$
\begin{aligned}
& \text { Find } x^{*} \in \mathrm{EP}(g, C) \text { such that } \\
& \qquad f\left(x^{*}, y\right) \geq 0 \quad \text { for all } y \in \operatorname{EP}(g, C) .
\end{aligned}
$$

So the bilevel equilibrium problem is the problem of finding $x^{*} \in \operatorname{EP}(f, \operatorname{EP}(g, C))$.

Yuying et al. [10] proposed two iterative methods to approximate a solution of the bilevel equilibrium problem. The purpose of this paper is to show that their two methods can

(c) The Author(s) 2021. This article is licensed under a Creative Commons Attribution 4.0 International License, which permits use sharing, adaptation, distribution and reproduction in any medium or format, as long as you give appropriate credit to the original author(s) and the source, provide a link to the Creative Commons licence, and indicate if changes were made. The images or other third party material in this article are included in the article's Creative Commons licence, unless indicated otherwise in a credit line to the material. If material is not included in the article's Creative Commons licence and your intended use is not permitted by statutory regulation or exceeds the permitted use, you will need to obtain permission directly from the copyright holder. To view a copy of this licence, visit http://creativecommons.org/licenses/by/4.0/. 
be regarded as a particular case of the Halpern-type sequence introduced by Jaipranop and Saejung [6] with appropriate setting. Moreover, we obtain their results under weaker assumptions.

\section{Preliminaries}

Let $\mathcal{H}$ be a real Hilbert space with inner product $\langle\cdot, \cdot\rangle$ and induced norm $\|\cdot\|$. Denote by $\rightarrow$ and $\rightarrow$ the strong convergence and weak convergence, respectively, that is, $x_{n} \rightarrow x\left(x_{n} \rightarrow x\right.$, resp.) if and only if $\lim _{n \rightarrow \infty}\left\|x_{n}-x\right\|=0\left(\lim _{n \rightarrow \infty}\left\langle x_{n}-x, y\right\rangle=0\right.$ for all $y \in \mathcal{H}$, resp.). For a given sequence $\left\{x_{n}\right\}$, let $\omega_{w}\left\{x_{n}\right\}$ denote the set of all weak cluster points of $\left\{x_{n}\right\}$, that is, $z \in \omega_{w}\left\{x_{n}\right\}$ if and only if $x_{n_{k}} \rightarrow z$ for some subsequence $\left\{x_{n_{k}}\right\}$ of $\left\{x_{n}\right\}$.

For a closed convex subset $C$ of $\mathcal{H}$, the projection $P_{C}: \mathcal{H} \rightarrow C$ is defined as follows:

$$
P_{C} u:=x^{*} \quad \Longleftrightarrow \quad x^{*} \in C \text { satisfies }\left\|x^{*}-u\right\|=\min _{y \in C}\|u-y\| .
$$

For a given $u \in \mathcal{H}$, it is not difficult to see that the point $x^{*}$ above can be regarded as a solution of the equilibrium problem associated with the bifunction $g(x, y):=\langle u-x, x-y\rangle$ and a closed convex subset $C$. In fact, we have

$$
P_{C} u:=x^{*} \quad \Longleftrightarrow \quad x^{*} \in \mathrm{EP}(g, C) \quad \Longleftrightarrow g\left(x^{*}, y\right)=\left\langle u-x^{*}, x^{*}-y\right\rangle \geq 0
$$

for all $y \in C$.

Definition 1 A function $G: \mathcal{H} \rightarrow \mathbb{R}$ is said to be

(1) convex if $G(\alpha x+(1-\alpha) y) \leq \alpha G(x)+(1-\alpha) G(y)$ for all $x, y \in \mathcal{H}$ and $\alpha \in[0,1]$,

(2) lower semicontinuous if $G(y) \leq \liminf _{n \rightarrow \infty} G\left(y_{n}\right)$ whenever $\left\{y_{n}\right\}$ is a sequence in $\mathcal{H}$ such that $y_{n} \rightarrow y \in \mathcal{H}$,

(3) weakly upper semicontinuous if $\lim _{\sup _{n \rightarrow \infty}} G\left(y_{n}\right) \leq G(y)$ whenever $\left\{y_{n}\right\}$ is a sequence in $\mathcal{H}$ such that $y_{n} \rightarrow y \in \mathcal{H}$,

(4) subdifferentiable on $\mathcal{H}$ if $\partial G(x):=\{w \in \mathcal{H}:\langle w, y-x\rangle \leq G(y)-G(x)$ for all $y \in \mathcal{H}\} \neq \varnothing$ for all $x \in \mathcal{H}$.

We recall the notion of a Halpern-type sequence introduced by the present authors [6].

Definition 2 Suppose that $C$ and $F$ are two nonempty closed convex subsets of $\mathcal{H}$ such that $F \subset C$. We say that a sequence $\left\{x_{n}\right\} \subset C$ is a Halpern-type sequence with respect to $F$ if there exist a contraction $h: C \rightarrow C$, three sequences $\left\{u_{n}\right\},\left\{v_{n}\right\},\left\{w_{n}\right\}$ in $C$, and two sequences $\left\{\alpha_{n}\right\},\left\{\beta_{n}\right\}$ in $[0,1]$ such that the following conditions are satisfied:

(a) $\sum_{n=1}^{\infty} \alpha_{n}=\infty$ and $\lim \sup _{n \rightarrow \infty} \beta_{n}<1$;

(b) $x_{n+1}=\beta_{n} x_{n}+\left(1-\beta_{n}\right) w_{n}$ for all $n \geq 1$;

(c) $\max \left\{\left\|u_{n}-p\right\|,\left\|v_{n}-p\right\|\right\} \leq\left\|x_{n}-p\right\|$ for all $n \geq 1$ and $p \in F$;

(d) $\left\|w_{n}-p\right\| \leq\left\|y_{n}-p\right\|$ for all $n \geq 1$ and $p \in F$, where $y_{n}:=\alpha_{n} h\left(u_{n}\right)+\left(1-\alpha_{n}\right) v_{n}$.

In this case, we also say that $\left\{x_{n}\right\}$ is a Halpern sequence with respect to $F$ associated with $\left\{\alpha_{n}\right\},\left\{\beta_{n}\right\},\left\{u_{n}\right\},\left\{v_{n}\right\},\left\{w_{n}\right\}$, and $h$.

Remark 3 ([6]) Every Halpern-type sequence with respect to a nonempty closed convex set is bounded. 
Theorem 4 ([6]) Let $C$ and $F$ be two nonempty closed convex subsets of $\mathcal{H}$ such that $F \subset C$. Let $\left\{x_{n}\right\}$ be a Halpern-type sequence with respect to F associated with $\left\{\alpha_{n}\right\},\left\{\beta_{n}\right\},\left\{u_{n}\right\},\left\{v_{n}\right\}$, $\left\{w_{n}\right\}$, and $h$. Suppose, in addition, that $\lim _{n \rightarrow \infty} \alpha_{n}=0$. Then there exists a unique element $x^{*} \in F$ such that $x^{*}=P_{F} h\left(x^{*}\right)$, and the following three statements are equivalent:

(a) $x_{n} \rightarrow x^{*}$;

(b) $\omega_{w}\left\{v_{n}\right\} \subset F$;

(c) $\omega_{w}\left\{v_{n_{k}}\right\} \subset F$ whenever $\left\{x_{n_{k}}\right\}$ is a subsequence of $\left\{x_{n}\right\}$ such that

$$
\lim _{k \rightarrow \infty}\left(\left\|v_{n_{k}}-p\right\|-\left\|x_{n_{k}}-p\right\|\right)=0 \quad \text { for some } p \in F
$$

The notion of a Halpern-type sequence was introduced in [6] to obtain a strong convergence theorem of an iterative sequence. This is different from the notion of a Fejér sequence (for more detail, we refer to [2, Chap. 5]), which is related to the weak convergence. In fact, there exists a Fejér sequence that is not strongly convergent.

\section{Main results}

Throughout this section, we assume that two bifunctions $f, g: \mathcal{H} \times \mathcal{H} \rightarrow \mathbb{R}$ satisfy the condition $f(x, x)=g(x, x)=0$ for all $x \in \mathcal{H}$ and $C$ is a closed convex subset of $\mathcal{H}$. To simplify the notation, we assume that

$$
\Omega:=\mathrm{EP}(g, C) \neq \varnothing \quad \text { and } \quad \Omega^{*}:=\mathrm{EP}(f, \Omega) \text {. }
$$

\subsection{Some preliminaries on equilibrium problems}

We first prepare some tools in proving the main results in the next subsections. Let us recall the following conditions for a bifunction $G: \mathcal{H} \times \mathcal{H} \rightarrow \mathbb{R}$.

(A1) $G$ is pseudomonotone on $C$ with respect to $\operatorname{EP}(G, C)$, that is, $G\left(y, x^{*}\right) \leq 0$ for all $\left(y, x^{*}\right) \in C \times \mathrm{EP}(G, C)$.

(A2) $G$ is $\beta$-strongly monotone on $\mathcal{H}$, where $\beta>0$, that is, $G(x, y)+G(y, x) \leq-\beta\|x-y\|^{2}$ for all $x, y \in \mathcal{H}$.

(A3) $G$ is Lipschitz-type continuous on $\mathcal{H}$ with constants $L_{1}, L_{2}>0$, that is,

$$
G(x, z)-G(x, y)-G(y, z) \leq L_{1}\|x-y\|^{2}+L_{2}\|y-z\|^{2} \quad \text { for all } x, y, z \in \mathcal{H} .
$$

(A4) $G$ is jointly weakly continuous on $\mathcal{H} \times \mathcal{H}$, that is, $G\left(x_{n}, y_{n}\right) \rightarrow G(x, y)$ whenever $\left\{x_{n}\right\}$ and $\left\{y_{n}\right\}$ are two sequences in $\mathcal{H}$ such that $x_{n} \rightarrow x \in \mathcal{H}$ and $y_{n} \rightarrow y \in \mathcal{H}$.

(A5) For each $x \in \mathcal{H}, G(x, \cdot)$ is convex and lower semicontinuous on $\mathcal{H}$.

(A6) For each $y \in \mathcal{H}, G(\cdot, y)$ is weakly upper semicontinuous on $\mathcal{H}$.

Remark 5 ([2]) Let $G: \mathcal{H} \times \mathcal{H} \rightarrow \mathbb{R}$ be a bifunction, and let $x \in \mathcal{H}$.

(1) Suppose that $G(x, \cdot)$ is convex. Then $G(x, \cdot)$ is lower semicontinuous if and only if it is weakly lower semicontinuous.

(2) If $G(x, \cdot)$ is convex and lower semicontinuous on $\mathcal{H}$, then $G(x, \cdot)$ is subdifferentiable on $\mathcal{H}$, that is, the subdifferential

$\partial G(x, \cdot)(y):=\{z \in \mathcal{H}: G(x, y)+\langle z, w-y\rangle \leq G(x, w)$ for all $w \in \mathcal{H}\} \neq \varnothing$ for all $y \in \mathcal{H}$. Moreover, $\partial G(x, \cdot)(y)$ is bounded for all $y \in \mathcal{H}$.

(3) $G(x, \cdot)$ satisfies (A5) $\Longleftrightarrow G(x, \cdot)$ is convex and subdifferentiable on $\mathcal{H}$. 
(4) If $G$ satisfies (A4), then it satisfies (A6).

Lemma 6 ([7]) Assume that $g: \mathcal{H} \times \mathcal{H} \rightarrow \mathbb{R}$ satisfies (A1), (A5), and either (A3) or (A6). Then $\Omega$ is closed and convex.

Proof Set $\widehat{\Omega}:=\{\widehat{z} \in C: g(y, \widehat{z}) \leq 0$ for all $y \in C\}$. It follows from (A5) and the closedness and convexity of $C$ that $\widehat{\Omega}$ is closed and convex. It follows from (A1) that $\Omega \subset \widehat{\Omega}$. To complete the proof, we show that $\widehat{\Omega} \subset \Omega$. To see this, let $\widehat{z} \in \widehat{\Omega}$. Let $y \in C$ and $t \in(0,1)$. Since $(1-$ $t) \widehat{z}+t y \in C$, we get $g((1-t) \widehat{z}+t y, \widehat{z}) \leq 0$.

Case 1: $g$ satisfies (A3). Since $g$ satisfies (A3) and (A5), we have

$$
\begin{aligned}
0 & =g(\widehat{z}, \widehat{z}) \\
& \leq g(\widehat{z},(1-t) \widehat{z}+t y)+g((1-t) \widehat{z}+t y, \widehat{z})+\left(L_{1}+L_{2}\right)\|(1-t) \widehat{z}+t y-\widehat{z}\|^{2} \\
& \leq \operatorname{tg}(\widehat{z}, y)+\left(L_{1}+L_{2}\right) t^{2}\|\widehat{z}-y\|^{2} .
\end{aligned}
$$

Then $0 \leq g(\widehat{z}, y)+\left(L_{1}+L_{2}\right) t\|\widehat{z}-y\|^{2}$. Letting $t \downarrow 0$ gives $0 \leq g(\widehat{z}, y)$, that is, $\widehat{z} \in \Omega$. Hence $\widehat{\Omega} \subset \Omega$.

Case 2: $g$ satisfies (A6). Since $g$ satisfies (A5) and $g((1-t) \widehat{z}+t y, \widehat{z}) \leq 0$, we have

$$
\begin{aligned}
0 & =g((1-t) \widehat{z}+t y,(1-t) \widehat{z}+t y) \\
& \leq(1-t) g((1-t) \widehat{z}+t y, \widehat{z})+t g((1-t) \widehat{z}+t y, y) \\
& \leq \operatorname{tg}((1-t) \widehat{z}+t y, y) .
\end{aligned}
$$

This implies that $0 \leq g((1-t) \widehat{z}+t y, y)$. Since $g$ satisfies (A6), we have $0 \leq g(\widehat{z}, y)$, that is, $\widehat{z} \in \Omega$. Hence $\widehat{\Omega} \subset \Omega$.

Lemma 7 ([7]) Let $C$ be a nonempty closed convex subset of $\mathcal{H}$. Let $x_{1}, x_{2}, y \in C$ and $\lambda>0$, and let $g: \mathcal{H} \times \mathcal{H} \rightarrow \mathbb{R}$ be a bifunction such that $g(x, \cdot)$ is convex for all $x \in \mathcal{H}$. Then the following statements are equivalent.

- $y=\operatorname{argmin}\left\{\lambda g\left(x_{2}, w\right)+\frac{1}{2}\left\|w-x_{1}\right\|^{2}: w \in C\right\}$

- $\left\langle x_{1}-y, w-y\right\rangle \leq \lambda\left(g\left(x_{2}, w\right)-g\left(x_{2}, y\right)\right)$ for all $w \in C$.

In particular, $x=\operatorname{argmin}\left\{\lambda g(x, w)+\frac{1}{2}\|w-x\|^{2}: w \in C\right\}$ if and only if $g(x, w) \geq 0$ for all $w \in C$.

Recall that an element $x \in \mathcal{H}$ is a fixed point of a mapping $T: \mathcal{H} \rightarrow \mathcal{H}$ if $x=T x$. We denote the set of all fixed points of $T$ by $\operatorname{Fix}(T)$.

Lemma 8 Let $C$ be a nonempty closed convex subset of $\mathcal{H}$, and let $g: \mathcal{H} \times \mathcal{H} \rightarrow \mathbb{R}$ be a bifunction satisfying (A5). For each $n \geq 1$, let $T_{n}: \mathcal{H} \rightarrow C$ be defined by

$$
T_{n} x:=\operatorname{argmin}\left\{\lambda_{n} g(x, y)+\frac{1}{2}\|y-x\|^{2}: y \in C\right\}
$$

for $x \in \mathcal{H}$, where $0<\underline{\lambda} \leq \lambda_{n}$. Then $\operatorname{Fix}\left(T_{n}\right)=\Omega$ for all $n \geq 1$. Moreover, suppose in addition that one of the following conditions holds:

(I) $g$ satisfies (A4);

(II) $g$ satisfies (A6), and if $\left\{x_{n}^{\prime}\right\},\left\{y_{n}^{\prime}\right\} \subset \mathcal{H}$ are such that $x_{n}^{\prime}-y_{n}^{\prime} \rightarrow 0$, then $g\left(x_{n}^{\prime}, y_{n}^{\prime}\right) \rightarrow 0$. If $\left\{x_{n}\right\} \subset \mathcal{H}$ is a bounded sequence such that $x_{n}-T_{n} x_{n} \rightarrow 0$, then $\omega_{w}\left\{x_{n}\right\} \subset \Omega$. 
Proof The first statement is trivial. To prove the "Moreover" part, suppose that $\left\{x_{n}\right\} \subset \mathcal{H}$ is a bounded sequence such that $x_{n}-T_{n} x_{n} \rightarrow 0$. Note that $\omega_{w}\left\{x_{n}\right\}=\omega_{w}\left\{T_{n} x_{n}\right\} \subset C$. We assume that there exists a subsequence $\left\{x_{n_{k}}\right\}$ of $\left\{x_{n}\right\}$ such that $x_{n_{k}} \rightarrow x$ for some $x \in C$. By assumption we get $x_{n_{k}}-T_{n_{k}} x_{n_{k}} \rightarrow 0$ and $T_{n_{k}} x_{n_{k}} \rightarrow x$. From the definition of $T_{n_{k}} x_{n_{k}}$ with Lemma 7, we have

$$
\left\langle x_{n_{k}}-T_{n_{k}} x_{n_{k}}, y-T_{n_{k}} x_{n_{k}}\right\rangle \leq \lambda_{n_{k}}\left(g\left(x_{n_{k}}, y\right)-g\left(x_{n_{k}}, T_{n_{k}} x_{n_{k}}\right)\right) \quad \text { for all } y \in C \text {. }
$$

Note that $x_{n_{k}}-T_{n_{k}} x_{n_{k}} \rightarrow 0$ and the bifunction $g$ satisfies either (I) or (II). It follows from $0<\underline{\lambda} \leq \liminf _{k \rightarrow \infty} \lambda_{n_{k}}$ that $0 \leq g(x, y)$ for all $y \in C$. Hence $\omega_{w}\left\{x_{n}\right\} \subset \Omega$.

Finally, we prepare some tools for the bilevel equilibrium problems based on the diagonal subdifferential operators [5]. Suppose that $f: \mathcal{H} \times \mathcal{H} \rightarrow \mathbb{R}$ is a bifunction such that $f(x, \cdot)$ : $\mathcal{H} \rightarrow \mathbb{R}$ is convex and lower semicontinuous for each $x \in \mathcal{H}$. In particular, $\partial f(x, \cdot)(x) \neq$ $\varnothing$ for all $x \in \mathcal{H}$. The diagonal subdifferential operator $S_{f}: \mathcal{H} \rightarrow 2^{\mathcal{H}}$ is the multivalued function defined by

$$
S_{f}(x):=\partial f(x, \cdot)(x) \text { for all } x \in \mathcal{H} \text {. }
$$

We consider the following conditions.

(A7) $S_{f}$ is $L$-Lipschitz, that is, $\|u-v\| \leq L\|x-y\|$ for all $x, y \in \mathcal{H}$ and for all $(u, v) \in S_{f}(x) \times S_{f}(y)$.

(A8) The function $x \mapsto S_{f}(x)$ is bounded on each bounded subset of $\mathcal{H}$.

Remark 9 If $S_{f}$ satisfies (A7), then $S_{f}$ satisfies (A8), and $S_{f}$ is a single-valued mapping. In this case the notation $S_{f}(x)$ is interpreted as an element rather than a singleton.

Lemma 10 Assume that $f: \mathcal{H} \times \mathcal{H} \rightarrow \mathbb{R}$ satisfies (A2) with a constant $\beta$ and (A5). Then $S_{f}$ is strongly monotone with the constant $\beta$, that is,

$$
\langle u-v, x-y\rangle \geq \beta\|x-y\|^{2}
$$

for all $x, y \in \mathcal{H}$ and for all $(u, v) \in S_{f}(x) \times S_{f}(y)$.

Proof Suppose that $x, y \in \mathcal{H}$ and $(u, v) \in S_{f}(x) \times S_{f}(y)$. It follows that

$$
\begin{aligned}
& \langle u, y-x\rangle \leq f(x, x)+\langle u, y-x\rangle \leq f(x, y), \\
& \langle v, x-y\rangle \leq f(y, y)+\langle v, x-y\rangle \leq f(y, x) .
\end{aligned}
$$

In particular, $\langle u-v, y-x\rangle \leq-\beta\|x-y\|^{2}$, and this completes the proof.

Lemma 11 Assume that $f: \mathcal{H} \times \mathcal{H} \rightarrow \mathbb{R}$ satisfies (A2), (A5), (A7), and $0<\mu<2 \beta / L^{2}$. Then $I-\mu S_{f}$ is a contraction, where $I$ is the identity mapping.

Proof From $0<\mu<2 \beta / L^{2}$ we have $1-\mu L^{2}\left(\frac{2 \beta}{L^{2}}-\mu\right) \in(0,1)$. Let $x, y \in \mathcal{H}$ and $u:=S_{f}(x)$, $v:=S_{f}(y)$. It follows from (A7) that

$$
\|x-\mu u-(y-\mu v)\|^{2}=\|x-y\|^{2}-2 \mu\langle x-y, u-v\rangle+\mu^{2}\|u-v\|^{2}
$$




$$
\begin{aligned}
& \leq\|x-y\|^{2}-2 \mu \beta\|x-y\|^{2}+\mu^{2} L^{2}\|x-y\|^{2} \\
& =\left(1-\mu L^{2}\left(\frac{2 \beta}{L^{2}}-\mu\right)\right)\|x-y\|^{2} .
\end{aligned}
$$

Lemma 12 Assume that $f: \mathcal{H} \times \mathcal{H} \rightarrow \mathbb{R}$ satisfies (A2), (A5), (A7) and $g: \mathcal{H} \times \mathcal{H} \rightarrow \mathbb{R}$ satisfies (A1), (A5), and either (A3) or (A6). Let $\Omega \neq \varnothing$ and $0<\mu<2 \beta / L^{2}$. Then $\Omega^{*}=\left\{x^{*}\right\}$, where $x^{*}=P_{\Omega}\left(x^{*}-\mu S_{f}\left(x^{*}\right)\right)$.

Proof From Lemma 11 we obtain that $P_{\Omega} \circ\left(I-\mu S_{f}\right): \Omega \rightarrow \Omega$ is a contraction. By the Banach contraction principle and the completeness of $\Omega$ there exists $x^{*} \in \Omega$ such that $x^{*}=P_{\Omega}\left(x^{*}-\mu S_{f}\left(x^{*}\right)\right)$. To show that $x^{*} \in \Omega^{*}$, let $y \in \Omega$. Note that $\left\langle x^{*}-\mu S_{f}\left(x^{*}\right)-x^{*}, x^{*}-\right.$ $y\rangle \geq 0$. This implies that $\left\langle S_{f}\left(x^{*}\right), y-x^{*}\right\rangle \geq 0$. It follows from the definition of $S_{f}$ that $\left\langle S_{f}\left(x^{*}\right), y-x^{*}\right\rangle \leq f\left(x^{*}, y\right)$. In particular, $f\left(x^{*}, y\right) \geq 0$, and hence $x^{*} \in \Omega^{*}$. Suppose that there exists another element $x^{\prime} \in \Omega^{*}$. It follows that $f\left(x^{*}, x^{\prime}\right) \geq 0$ and $f\left(x^{\prime}, x^{*}\right) \geq 0$. In particular, it follows from (A2) of $f$ that

$$
0 \leq f\left(x^{*}, x^{\prime}\right)+f\left(x^{\prime}, x^{*}\right) \leq-\beta\left\|x^{*}-x^{\prime}\right\|^{2} .
$$

Hence $x^{\prime}=x^{*}$. This completes the proof.

\subsection{On the algorithm of Halpern-Korpelevič type}

In this subsection, we discuss the following assumption and algorithm.

Assumption 1 Let $C$ be a nonempty closed convex subset of $\mathcal{H}$, let $g: \mathcal{H} \times \mathcal{H} \rightarrow \mathbb{R}$ be a bifunction, and let $h: \mathcal{H} \rightarrow \mathcal{H}$ be a contraction. Assume that

(i) $g$ satisfies (A1), (A3), (A5), and (A6);

(ii) A sequence $\left\{\alpha_{n}\right\} \subset(0,1)$ is such that $\lim _{n \rightarrow \infty} \alpha_{n}=0$ and $\sum_{n=1}^{\infty} \alpha_{n}=\infty$;

(iii) $0<\underline{\lambda} \leq \lambda_{n} \leq \bar{\lambda}<\min \left\{\frac{1}{2 L_{1}}, \frac{1}{2 L_{2}}\right\}$;

(iv) A sequence $\left\{\beta_{n}\right\} \subset[0,1]$ is such that $\lim _{\sup _{n \rightarrow \infty}} \beta_{n}<1$.

Algorithm 1 Let $\left\{x_{n}\right\} \subset \mathcal{H}$ be a sequence defined by

$$
\left\{\begin{array}{l}
x_{1} \in \mathcal{H} \text { is arbitrarily chosen; } \\
y_{n}:=\operatorname{argmin}\left\{\lambda_{n} g\left(x_{n}, y\right)+\frac{1}{2}\left\|y-x_{n}\right\|^{2}: y \in C\right\} \\
v_{n}:=\operatorname{argmin}\left\{\lambda_{n} g\left(y_{n}, y\right)+\frac{1}{2}\left\|y-x_{n}\right\|^{2}: y \in C\right\} ; \\
x_{n+1}:=\beta_{n} x_{n}+\left(1-\beta_{n}\right)\left(\alpha_{n} h\left(v_{n}\right)+\left(1-\alpha_{n}\right) v_{n}\right) \quad \text { for } n \geq 1 .
\end{array}\right.
$$

Lemma 13 Assume that $g: \mathcal{H} \times \mathcal{H} \rightarrow \mathbb{R}$ satisfies (A1) and (A3) with constants $L_{1}$ and $L_{2}$ and that $g(x, \cdot): \mathcal{H} \rightarrow \mathbb{R}$ is convex for all $x \in \mathcal{H}$. Let $x \in \mathcal{H}$ and $\lambda \in(0, \infty)$, and let

$$
\begin{aligned}
& y:=\operatorname{argmin}\left\{\lambda g(x, w)+\frac{1}{2}\|w-x\|^{2}: w \in C\right\} \\
& v:=\operatorname{argmin}\left\{\lambda g(y, w)+\frac{1}{2}\|w-x\|^{2}: w \in C\right\} .
\end{aligned}
$$

If $p \in \Omega$, then

$$
\|v-p\|^{2} \leq\|x-p\|^{2}-\left(1-2 \lambda L_{1}\right)\|x-y\|^{2}-\left(1-2 \lambda L_{2}\right)\|y-v\|^{2} .
$$


Proof Let $p \in \Omega$. By the definitions of $y$ and $v$ it follows from Lemma 7 that

$$
\begin{aligned}
& \|x-y\|^{2}+\|y-v\|^{2}-\|x-v\|^{2}=2\langle x-y, v-y\rangle \leq 2 \lambda(g(x, v)-g(x, y)) ; \\
& \|x-v\|^{2}+\|v-p\|^{2}-\|x-p\|^{2}=2\langle x-v, p-v\rangle \leq 2 \lambda(g(y, p)-g(y, v)) .
\end{aligned}
$$

This implies that

$$
\|v-p\|^{2} \leq\|x-p\|^{2}-\|x-y\|^{2}-\|y-v\|^{2}+2 \lambda(g(x, v)-g(x, y)+g(y, p)-g(y, v)) .
$$

It follows from (A3) that there are $L_{1}, L_{2}>0$ such that

$$
g(x, v)-g(x, y)-g(y, v) \leq L_{1}\|x-y\|^{2}+L_{2}\|y-v\|^{2} .
$$

Note that $g(y, p) \leq 0$. Hence

$$
\|v-p\|^{2} \leq\|x-p\|^{2}-\left(1-2 \lambda L_{1}\right)\|x-y\|^{2}-\left(1-2 \lambda L_{2}\right)\|y-v\|^{2} .
$$

This completes the proof.

Lemma 14 Let $C$ be a nonempty closed convex subset of $\mathcal{H}$, and let $g: \mathcal{H} \times \mathcal{H} \rightarrow \mathbb{R}$ be a bifunction satisfying (A1) and (A3) with constants $L_{1}$ and $L_{2}$, (A5), and (A6). Let $\left\{x_{n}\right\}$ be a bounded sequence in $\mathcal{H}$, and let

$$
\begin{aligned}
& y_{n}:=\operatorname{argmin}\left\{\lambda_{n} g\left(x_{n}, w\right)+\frac{1}{2}\left\|w-x_{n}\right\|^{2}: w \in C\right\}, \\
& v_{n}:=\operatorname{argmin}\left\{\lambda_{n} g\left(y_{n}, w\right)+\frac{1}{2}\left\|w-x_{n}\right\|^{2}: w \in C\right\},
\end{aligned}
$$

where $0<\underline{\lambda} \leq \lambda_{n} \leq \bar{\lambda}<\min \left\{\frac{1}{2 L_{1}}, \frac{1}{2 L_{2}}\right\}$ for all $n \geq 1$. If $\lim _{n \rightarrow \infty}\left(\left\|v_{n}-p\right\|-\left\|x_{n}-p\right\|\right)=0$ for some $p \in \Omega$, then $\omega_{w}\left\{x_{n}\right\} \subset \Omega$.

Proof We assume that $\lim _{n \rightarrow \infty}\left(\left\|v_{n}-p\right\|-\left\|x_{n}-p\right\|\right)=0$ for some $p \in \Omega$. Note that $\left\{x_{n}\right\}$ is bounded, and hence so is $\left\{v_{n}\right\}$. This implies that

$$
\lim _{n \rightarrow \infty}\left(\left\|v_{n}-p\right\|^{2}-\left\|x_{n}-p\right\|^{2}\right)=0
$$

By Lemma 13 we have

$$
\left\|v_{n}-p\right\|^{2} \leq\left\|x_{n}-p\right\|^{2}-\left(1-2 \lambda_{n} L_{1}\right)\left\|x_{n}-y_{n}\right\|^{2}-\left(1-2 \lambda_{n} L_{2}\right)\left\|y_{n}-v_{n}\right\|^{2} .
$$

Note that $\liminf _{n \rightarrow \infty}\left(1-2 \lambda_{n} L_{1}\right)>0$ and $\liminf _{n \rightarrow \infty}\left(1-2 \lambda_{n} L_{2}\right)>0$. It follows that $\lim _{n \rightarrow \infty}\left\|x_{n}-y_{n}\right\|=\lim _{n \rightarrow \infty}\left\|y_{n}-v_{n}\right\|=0$. To show that $\omega_{w}\left\{x_{n}\right\} \subset \Omega$, let $x \in \omega_{w}\left\{x_{n}\right\}$. Then $x \in C$, and there exists a subsequence $\left\{x_{n_{k}}\right\}$ of $\left\{x_{n}\right\}$ such that $x_{n_{k}} \rightarrow x$. Let $y \in C$. It follows from Lemma 7 and the definitions of $y_{n}$ and $v_{n}$ that

$$
\left\langle x_{n}-y_{n}, v_{n}-y_{n}\right\rangle \leq \lambda_{n}\left(g\left(x_{n}, v_{n}\right)-g\left(x_{n}, y_{n}\right)\right)
$$




$$
\left\langle x_{n}-v_{n}, y-v_{n}\right\rangle \leq \lambda_{n}\left(g\left(y_{n}, y\right)-g\left(y_{n}, v_{n}\right)\right) .
$$

In particular, $\liminf _{n \rightarrow \infty}\left(g\left(x_{n}, v_{n}\right)-g\left(x_{n}, y_{n}\right)\right) \geq 0$ and $\liminf _{n \rightarrow \infty}\left(g\left(y_{n}, y\right)-g\left(y_{n}, v_{n}\right)\right) \geq 0$. It follows from (A3) that

$$
\limsup _{n \rightarrow \infty}\left(g\left(x_{n}, v_{n}\right)-g\left(x_{n}, y_{n}\right)-g\left(y_{n}, v_{n}\right)\right) \leq L_{1} \lim _{n \rightarrow \infty}\left\|x_{n}-y_{n}\right\|^{2}+L_{2} \lim _{n \rightarrow \infty}\left\|y_{n}-v_{n}\right\|^{2}=0 .
$$

This implies that $\liminf _{n \rightarrow \infty} g\left(y_{n}, y\right) \geq 0$. It follows from (A6) and $y_{n_{k}} \rightarrow x$ that $g(x, y) \geq 0$. This implies that $x \in \Omega$, and the proof is finished.

We are ready to present the first main result of the paper.

Theorem 15 Let $\left\{x_{n}\right\}$ be a sequence generated by Algorithm 1 satisfying Assumption 1. Then $\left\{x_{n}\right\}$ converges strongly to $x^{*}=P_{\Omega} h\left(x^{*}\right)$.

Proof Let $p \in \Omega$. By Lemma 13 we have

$$
\left\|v_{n}-p\right\|^{2} \leq\left\|x_{n}-p\right\|^{2}-\left(1-2 \lambda_{n} L_{1}\right)\left\|x_{n}-y_{n}\right\|^{2}-\left(1-2 \lambda_{n} L_{2}\right)\left\|y_{n}-v_{n}\right\|^{2} .
$$

In particular, $\left\|v_{n}-p\right\| \leq\left\|x_{n}-p\right\|$ for all $n \geq 1$, and hence $\left\{x_{n}\right\}$ is a Halpern sequence with respect to $\Omega$ associated with $\left\{\alpha_{n}\right\},\left\{\beta_{n}\right\},\left\{v_{n}\right\},\left\{v_{n}\right\},\left\{w_{n}\right\}$, and $h$, where $w_{n}:=\alpha_{n} h\left(v_{n}\right)+$ $\left(1-\alpha_{n}\right) v_{n}$. Moreover, $\left\{x_{n}\right\}$ is bounded, and so is $\left\{v_{n}\right\}$ by Remark 3. Next, we prove that $\omega_{w}\left\{v_{n_{k}}\right\} \subset \Omega$ whenever $\left\{x_{n_{k}}\right\}$ is a subsequence of $\left\{x_{n}\right\}$ such that $\lim _{k \rightarrow \infty}\left(\left\|v_{n_{k}}-q\right\|-\| x_{n_{k}}-\right.$ $q \|)=0$ for some $p \in \Omega$. To see this, let $\left\{x_{n_{k}}\right\}$ and $\left\{v_{n_{k}}\right\}$ be such subsequences. Note that $\lim _{k \rightarrow \infty}\left\|v_{n_{k}}-y_{n_{k}}\right\|=\lim _{k \rightarrow \infty}\left\|y_{n_{k}}-x_{n_{k}}\right\|=0$. Hence $\lim _{k \rightarrow \infty}\left\|v_{n_{k}}-x_{n_{k}}\right\|=0$. By Lemma $14, \omega_{w}\left\{v_{n_{k}}\right\}=\omega_{w}\left\{x_{n_{k}}\right\} \subset \Omega$, which leads to the conclusion that $x_{n} \rightarrow x^{*}=P_{\Omega} h\left(x^{*}\right)$ by Theorem 4 .

We now apply our theorem to improve Theorem 3.1 of Yuying et al. [10].

Theorem 16 Let $C$ be a nonempty closed convex subset of $\mathcal{H}$, and let $f, g: \mathcal{H} \times \mathcal{H} \rightarrow \mathbb{R}$ be two bifunctions. Assume that

(i) g satisfies (A1), (A3), (A5), and (A6);

(ii) $f$ satisfies (A2), (A5), and (A7);

(iii) $0<\mu<2 \beta / L^{2}$;

(iv) A sequence $\left\{\alpha_{n}\right\} \subset(0,1)$ is such that $\lim _{n \rightarrow \infty} \alpha_{n}=0$ and $\sum_{n=1}^{\infty} \alpha_{n}=\infty$;

(v) $0<\underline{\lambda} \leq \lambda_{n} \leq \bar{\lambda}<\min \left\{\frac{1}{2 L_{1}}, \frac{1}{2 L_{2}}\right\}$ for all $n \geq 1$;

(vi) $0 \leq \beta_{n} \leq 1-\alpha_{n}$ for all $n \geq 1$, and $\lim _{\sup _{n \rightarrow \infty}} \beta_{n}<1$.

Let $\left\{x_{n}\right\} \subset \mathcal{H}$ be a sequence defined by

$$
\left\{\begin{array}{l}
x_{1} \in \mathcal{H} \text { is arbitrarily chosen; } \\
y_{n}:=\operatorname{argmin}\left\{\lambda_{n} g\left(x_{n}, y\right)+\frac{1}{2}\left\|y-x_{n}\right\|^{2}: y \in C\right\} ; \\
v_{n}:=\operatorname{argmin}\left\{\lambda_{n} g\left(y_{n}, y\right)+\frac{1}{2}\left\|y-x_{n}\right\|^{2}: y \in C\right\} ; \\
u_{n}:=S_{f}\left(v_{n}\right) ; \\
x_{n+1}:=\beta_{n} x_{n}+\left(1-\beta_{n}\right) v_{n}-\alpha_{n} \mu u_{n} \quad \text { for } n \geq 1 .
\end{array}\right.
$$

Then $\left\{x_{n}\right\}$ converges strongly to $x^{*}=P_{\Omega}\left(x^{*}-\mu S_{f}\left(x^{*}\right)\right)$. 
Proof Note that

$$
\begin{aligned}
x_{n+1} & :=\beta_{n} x_{n}+\left(1-\beta_{n}\right) v_{n}-\alpha_{n} \mu u_{n} \\
& =\beta_{n} x_{n}+\alpha_{n}\left(v_{n}-\mu u_{n}\right)+\left(1-\beta_{n}-\alpha_{n}\right) v_{n} \\
& =\beta_{n} x_{n}+\left(1-\beta_{n}\right)\left(\frac{\alpha_{n}}{1-\beta_{n}}\left(I-\mu S_{f}\right) v_{n}+\left(1-\frac{\alpha_{n}}{1-\beta_{n}}\right) v_{n}\right) .
\end{aligned}
$$

By Lemma $11, I-\mu S_{f}$ is a contraction. Note that $\frac{\alpha_{n}}{1-\beta_{n}} \in(0,1)$ for all $n \geq 1, \lim _{n \rightarrow \infty} \frac{\alpha_{n}}{1-\beta_{n}}=0$, and $\sum_{n=1}^{\infty} \frac{\alpha_{n}}{1-\beta_{n}}=\infty$. From Theorem 15 we conclude that $\left\{x_{n}\right\}$ converges strongly to $x^{*}=$ $P_{\Omega}\left(x^{*}-\mu S_{f}\left(x^{*}\right)\right)$.

Remark 17 Theorem 16 improves [10, Theorem 3.1] in the following ways.

(a) We exclude conditions (A6) and (A8) for the bifunction $f$ and condition (A4) for $g$.

(b) The condition $\lim _{n \rightarrow \infty} \beta_{n}<1$ is replaced by the weaker one $\lim _{\sup } \operatorname{su}_{n \rightarrow \infty} \beta_{n}<1$.

We now discuss two related results concerning the Halpern-Korpelevič algorithm. The first one is from [9, Theorem 3.2], which can be easily deduced from Theorem 15.

Corollary 18 ([9, Theorem 3.2 where $S:=I])$ Let $C$ be a nonempty closed convex subset of $\mathcal{H}$ and let $g: \mathcal{H} \times \mathcal{H} \rightarrow \mathbb{R}$ be a bifunction satisfying (A1), (A3), (A5), and (A6). Assume that $F: \mathcal{H} \rightarrow \mathcal{H}$ is $\gamma$-Lipschitz continuous and $\beta$-strongly monotone. Assume that

(i) A sequence $\left\{\alpha_{n}\right\} \subset(0,1)$ is such that $\lim _{n \rightarrow \infty} \alpha_{n}=0$ and $\sum_{n=1}^{\infty} \alpha_{n}=\infty$;

(ii) $0<\underline{\lambda} \leq \lambda_{n} \leq \bar{\lambda}<\min \left\{\frac{1}{2 L_{1}}, \frac{1}{2 L_{2}}\right\}$ for all $n \geq 1$.

Let $\left\{x_{n}\right\} \subset \mathcal{H}$ be the sequence defined by

$$
\left\{\begin{array}{l}
x_{1} \in \mathcal{H} \text { is arbitrarily chosen; } \\
y_{n}:=\operatorname{argmin}\left\{\lambda_{n} g\left(x_{n}, y\right)+\frac{1}{2}\left\|y-x_{n}\right\|^{2}: y \in C\right\} \\
v_{n}:=\operatorname{argmin}\left\{\lambda_{n} g\left(y_{n}, y\right)+\frac{1}{2}\left\|y-x_{n}\right\|^{2}: y \in C\right\} \\
x_{n+1}:=v_{n}-\alpha_{n} F v_{n} \quad \text { for } n \geq 1 .
\end{array}\right.
$$

Then $\left\{x_{n}\right\}$ converges strongly to $x^{*}=P_{\Omega}\left(x^{*}-F x^{*}\right)$.

Proof We can rewrite

$$
x_{n+1}=\frac{\alpha_{n}}{\mu}(I-\mu F) v_{n}+\left(1-\frac{\alpha_{n}}{\mu}\right) v_{n} .
$$

Note that $I-\mu F$ is a contraction whenever $0<\mu<2 \beta / \gamma^{2}$. From Theorem 15 with $\beta_{n}:=0$ and $h:=I-\mu F$, we conclude that $\left\{x_{n}\right\}$ converges strongly to $x^{*}=P_{\Omega}\left(x^{*}-\mu F x^{*}\right)=P_{\Omega}\left(x^{*}-\right.$ $\left.F x^{*}\right)$. The latter equality holds because of the property of the projection $P_{\Omega}$.

The second result is from [1, Theorem 3.3], where $T:=I, \beta_{n}:=0$ for $n \geq 1$, and $h(x):=x_{1}$ for $x \in \mathcal{H}$. To conclude the result, we need the assumption that the iterative sequence $\left\{x_{n}\right\}$ satisfies the condition $\lim _{n \rightarrow \infty}\left\|x_{n+1}-x_{n}\right\|=0$.

Corollary 19 ([1, Theorem 3.3 with $T:=I])$ Let $C$ be a nonempty closed convex subset of $\mathcal{H}$, let $g: \mathcal{H} \times \mathcal{H} \rightarrow \mathbb{R}$ be a bifunction satisfying (A3) and (A5), and suppose $g$ is pseudomonotone on $C$, that is, $g(x, y) \geq 0 \Rightarrow g(y, x) \leq 0$ for all $x, y \in \mathcal{H}$. Assume that 
(i) A sequence $\left\{\alpha_{n}\right\} \subset(0,1)$ is such that $\lim _{n \rightarrow \infty} \alpha_{n}=0$ and $\sum_{n=1}^{\infty} \alpha_{n}=\infty$;

(ii) $0<\lambda_{n} \leq \min \left\{\frac{1}{2 L_{1}}, \frac{1}{2 L_{2}}\right\}$ and $\lambda_{n}<\frac{1-\delta}{2 L_{1}}$ for all $n \geq 1$, where $\delta \in(0,1)$.

Let $\left\{x_{n}\right\} \subset \mathcal{H}$ be the sequence defined by

$$
\left\{\begin{array}{l}
x_{1} \in \mathcal{H} \text { is arbitrarily chosen } \\
y_{n}:=\operatorname{argmin}\left\{\lambda_{n} g\left(x_{n}, y\right)+\frac{1}{2}\left\|y-x_{n}\right\|^{2}: y \in C\right\} \\
v_{n}:=\operatorname{argmin}\left\{\lambda_{n} g\left(y_{n}, y\right)+\frac{1}{2}\left\|y-x_{n}\right\|^{2}: y \in C\right\} \\
x_{n+1}:=\alpha_{n} x_{1}+\left(1-\alpha_{n}\right) v_{n} \quad \text { for } n \geq 1 .
\end{array}\right.
$$

If $\lim _{n \rightarrow \infty}\left\|x_{n+1}-x_{n}\right\|=0$, then $\left\{x_{n}\right\}$ converges strongly to $x^{*}=P_{\Omega} x_{1}$.

As shown in [6], this result is not correct. Indeed, let $C=\mathcal{H}=\mathbb{R}$, and let $g(x, y):=\langle x, y-x\rangle$, $\alpha_{n}:=1 /(n+1), \lambda_{n}:=1 / 2^{n}$, and $x_{1}:=1$. Then $\Omega=\{0\}$ and $x_{n} \rightarrow 1 \notin \Omega$.

\subsection{On the extragradient-like algorithm with line search technique}

In this subsection, we modify the algorithm to avoid the prior knowledge of the values $L_{1}$ and $L_{2}$ as was the case in the previous algorithm.

Assumption 2 Let $C$ be a nonempty closed convex subset of $\mathcal{H}$, let $g: \mathcal{H} \times \mathcal{H} \rightarrow \mathbb{R}$ be a bifunction satisfying (A1), (A4), and (A5), and let $h: \mathcal{H} \rightarrow \mathcal{H}$ be a contraction. Assume that

(i) $\rho \in(0,2)$ and $\gamma \in(0,1)$;

(ii) A sequence $\left\{\alpha_{n}\right\} \subset(0,1)$ is such that $\lim _{n \rightarrow \infty} \alpha_{n}=0$ and $\sum_{n=1}^{\infty} \alpha_{n}=\infty$;

(iii) $\left\{\lambda_{n}\right\} \subset[\underline{\lambda}, \bar{\lambda}] \subset(0, \infty)$ and $\left\{\xi_{n}\right\} \subset[\underline{\xi}, \bar{\xi}] \subset(0,2)$ for all $n \geq 1$.

For each $x \in C$ and $\lambda>0$, let

$$
y:=\operatorname{argmin}\left\{\lambda g(x, w)+\frac{1}{2}\|w-x\|^{2}: w \in C\right\} .
$$

Suppose that $y \neq x$. It follows from [8] that there exists the smallest positive integer $m$ such that

$$
g(z, x)-g(z, y) \geq \frac{\rho}{2 \lambda}\|x-y\|^{2},
$$

where $z:=\left(1-\gamma^{m}\right) x+\gamma^{m} y$. Moreover, it was proved in [8] that $g(z, x)>0$ and $0 \notin \partial g(z, \cdot)(x)$.

Algorithm 2 Let $\left\{x_{n}\right\} \subset C$ be a sequence defined by $x_{1} \in C$ arbitrarily chosen, and let

$$
y_{n}:=\operatorname{argmin}\left\{\lambda_{n} g\left(x_{n}, y\right)+\frac{1}{2}\left\|y-x_{n}\right\|^{2}: y \in C\right\}
$$

If $y_{n}=x_{n}$, then $v_{n}:=x_{n}$. If $y_{n} \neq x_{n}$, then (Armijo line search rule) find $m(n)$ as the smallest positive integer $m$ satisfying

$$
g\left(\left(1-\gamma^{m}\right) x_{n}+\gamma^{m} y_{n}, x_{n}\right)-g\left(\left(1-\gamma^{m}\right) x_{n}+\gamma^{m} y_{n}, y_{n}\right) \geq \frac{\rho}{2 \lambda_{n}}\left\|x_{n}-y_{n}\right\|^{2}
$$


In particular, let $z_{n}:=\left(1-\gamma^{m(n)}\right) x_{n}+\gamma^{m(n)} y_{n}$. Choose $t_{n} \in \partial g\left(z_{n}, \cdot\right)\left(x_{n}\right)$ and $\sigma_{n}:=g\left(z_{n}, x_{n}\right) /$ $\left\|t_{n}\right\|^{2}$. Next,

$$
\begin{aligned}
& v_{n}:=P_{C}\left(x_{n}-\xi_{n} \sigma_{n} t_{n}\right) ; \\
& x_{n+1}:=P_{C}\left(\alpha_{n} h\left(v_{n}\right)+\left(1-\alpha_{n}\right) v_{n}\right) \quad \text { for } n \geq 1 .
\end{aligned}
$$

Lemma 20 Let $C$ be a nonempty closed convex subset of $\mathcal{H}$. Let $x \in C$, and let $\rho \in(0,2)$, $\gamma \in(0,1)$, and $\lambda \in(0, \infty)$. Assume that $g: \mathcal{H} \times \mathcal{H} \rightarrow \mathbb{R}$ satisfies (A1), (A4), and (A5). Let

$$
y:=\operatorname{argmin}\left\{\lambda g(x, w)+\frac{1}{2}\|w-x\|^{2}: w \in C\right\} .
$$

Assume that $y \neq x$. Let $m$ be the smallest positive integer such that

$$
g\left(\left(1-\gamma^{m}\right) x+\gamma^{m} y, x\right)-g\left(\left(1-\gamma^{m}\right) x+\gamma^{m} y, y\right) \geq \frac{\rho}{2 \lambda}\|x-y\|^{2},
$$

and let $z:=\left(1-\gamma^{m}\right) x+\gamma^{m} y$. Let $t \in \partial g(z, \cdot)(x)$ and $\sigma:=g(z, x) /\|t\|^{2}$. Then the following statements are true.

(i) If $v:=P_{C}(x-\xi \sigma t)$ where $\xi \in(0,2)$ and $p \in \Omega$, then

$$
\|v-p\|^{2} \leq\|x-p\|^{2}-\xi(2-\xi) \sigma^{2}\|t\|^{2}
$$

(ii) If $v:=P_{C \cap D}(x)$ where $D:=\{w \in \mathcal{H}:\langle t, x-w\rangle \geq g(z, x)\}$ and $p \in \Omega$, then

$$
\|v-p\|^{2} \leq\|x-p\|^{2}-\sigma^{2}\|t\|^{2}
$$

Proof Let $p \in \Omega$. Since $g(z, x)>0$ and $0 \notin \partial g(z, \cdot)(x)$, we have $\sigma>0$. From (A1) and $z \in C$ we have $g(z, p) \leq 0$. Since $t \in \partial g(z, \cdot)(x)$, we get $\langle t, x-p\rangle \geq g(z, x)-g(z, p) \geq g(z, x)$.

(i) Since $\langle t, x-p\rangle \geq g(z, x)=\sigma\|t\|^{2}$ and $\sigma>0$, we have

$$
\begin{aligned}
\|v-p\|^{2} & \leq\|x-\xi \sigma t-p\|^{2} \\
& =\|x-p\|^{2}-2 \xi \sigma\langle t, x-p\rangle+\xi^{2} \sigma^{2}\|t\|^{2} \\
& \leq\|x-p\|^{2}-2 \xi(\sigma\|t\|)^{2}+\xi^{2} \sigma^{2}\|t\|^{2} \\
& =\|x-p\|^{2}-\xi(2-\xi) \sigma^{2}\|t\|^{2} .
\end{aligned}
$$

(ii) Since $C \cap D \subset D$, we have $P_{C \cap D}(x)=P_{C \cap D}\left(P_{D} x\right)$. Note that $P_{D} x=x-\left(g(z, x) /\|t\|^{2}\right) t=$ $x-\sigma t$. It follows that $v:=P_{C \cap D}(x)=P_{C \cap D}\left(P_{D} x\right)=P_{C \cap D}(x-\sigma t)$. Since $\langle t, x-p\rangle \geq g(z, x)$, we obtain $p \in D$. Hence $p \in C \cap D$. Following the proof of (i) with $\xi=1$, we have

$$
\|v-p\|^{2} \leq\|x-\sigma t-p\|^{2} \leq\|x-p\|^{2}-\sigma^{2}\|t\|^{2} .
$$

The following lemma is related to [8, Proposition 4.3].

Lemma 21 Let $g: \mathcal{H} \times \mathcal{H} \rightarrow \mathbb{R}$ satisfy (A4) and (A5). Let $\left\{x_{n}\right\}$ and $\left\{z_{n}\right\}$ be bounded sequences in $\mathcal{H}$, and let $t_{n} \in \partial g\left(z_{n}, \cdot\right)\left(x_{n}\right)$. Then $\left\{t_{n}\right\}$ is bounded. 
Proof Suppose that $\left\{t_{n}\right\}$ is not bounded. Passing to a suitable subsequence, we may assume that $\left\|t_{n_{k}}\right\| \rightarrow \infty$ and $x_{n_{k}} \rightarrow x$ and $z_{n_{k}} \rightarrow z$ for some $x, z \in \mathcal{H}$. Since $t_{n_{k}} \in \partial g\left(z_{n_{k}}, \cdot\right)\left(x_{n_{k}}\right)$, we have $\left\langle t_{n_{k}}, w-x_{n_{k}}\right\rangle \leq g\left(z_{n_{k}}, w\right)-g\left(z_{n_{k}}, x_{n_{k}}\right)$ for all $w \in \mathcal{H}$. Let $y \in \mathcal{H}$. This implies that

$$
g\left(z_{n_{k}}, x_{n_{k}}\right)-g\left(z_{n_{k}},-y+x_{n_{k}}\right) \leq\left\langle t_{n_{k}}, y\right\rangle \leq g\left(z_{n_{k}}, y+x_{n_{k}}\right)-g\left(z_{n_{k}}, x_{n_{k}}\right) .
$$

It follows from (A4) that

$$
\begin{aligned}
& \lim _{k \rightarrow \infty}\left(g\left(z_{n_{k}}, x_{n_{k}}\right)-g\left(z_{n_{k}},-y+x_{n_{k}}\right)\right)=g(z, x)-g(z,-y+x), \\
& \lim _{k \rightarrow \infty}\left(g\left(z_{n_{k}}, y+x_{n_{k}}\right)-g\left(z_{n_{k}}, x_{n_{k}}\right)\right)=g(z, y+x)-g(z, x) .
\end{aligned}
$$

In particular, there exists $M_{y}>0$ such that $\left|\left\langle t_{n_{k}}, y\right\rangle\right| \leq M_{y}$ for all $k \geq 1$. By the uniform boundedness principle the sequence $\left\{t_{n_{k}}\right\}$ is bounded, which is a contradiction.

We can prove the following lemma as in the proof of [4, Lemma 4]. In fact, we can assume that $\left\{\lambda_{n}\right\} \subset(0, \bar{\lambda}] \subset(0, \infty)$ instead of $\lambda_{n}=1$ for all $n \geq 1$.

Lemma 22 Let $g: \mathcal{H} \times \mathcal{H} \rightarrow \mathbb{R}$ satisfy (A4) and (A5), and let $\left\{\lambda_{n}\right\} \subset(0, \infty)$. Let $\left\{x_{n}\right\}$ be a sequence in $C$, and for each $n \geq 1$, let

$$
y_{n}:=\operatorname{argmin}\left\{\lambda_{n} g\left(x_{n}, y\right)+\frac{1}{2}\left\|y-x_{n}\right\|^{2}: y \in C\right\} .
$$

If $\left\{x_{n}\right\}$ and $\left\{\lambda_{n}\right\}$ are bounded, then so is $\left\{y_{n}\right\}$.

Proof Note that

$$
\left\|x_{n}-y_{n}\right\|^{2}=\left\langle x_{n}-y_{n}, x_{n}-y_{n}\right\rangle \leq \lambda_{n}\left(g\left(x_{n}, x_{n}\right)-g\left(x_{n}, y_{n}\right)\right)=-\lambda_{n} g\left(x_{n}, y_{n}\right) .
$$

For $n \geq 1$, let $w_{n} \in S_{g}\left(x_{n}\right)$. Then

$$
-g\left(x_{n}, y_{n}\right) \leq\left\langle w_{n}, x_{n}-y_{n}\right\rangle \leq\left\|w_{n}\right\|\left\|x_{n}-y_{n}\right\|
$$

In particular, $\left\|x_{n}-y_{n}\right\|^{2} \leq \lambda_{n}\left\|w_{n}\right\|\left\|x_{n}-y_{n}\right\|$, and hence $\left\|x_{n}-y_{n}\right\| \leq \lambda_{n}\left\|w_{n}\right\|$. Since $\left\{x_{n}\right\}$ and $\left\{\lambda_{n}\right\}$ are bounded and $w_{n} \in S_{g}\left(x_{n}\right):=\partial g\left(x_{n}, \cdot\right)\left(x_{n}\right)$, it follows from Lemma 21 that $\left\{y_{n}\right\}$ is bounded.

Lemma 23 Let $\left\{x_{n}\right\}$ be a bounded sequence in C. Let $\rho \in(0,2)$ and $\gamma \in(0,1)$, and let $\left\{\lambda_{n}\right\} \subset(0, \bar{\lambda}] \subset(0, \infty)$ and $\left\{\xi_{n}\right\} \subset[\xi, \bar{\xi}] \subset(0,2)$. Assume that $g: \mathcal{H} \times \mathcal{H} \rightarrow \mathbb{R}$ satisfies (A1), (A4), and (A5). Define the sequence $\left\{y_{n}\right\}$ by

$$
y_{n}:=\operatorname{argmin}\left\{\lambda_{n} g\left(x_{n}, w\right)+\frac{1}{2}\left\|w-x_{n}\right\|^{2}: w \in C\right\} .
$$

Assume that $y_{n} \neq x_{n}$ for all $n \geq 1$. Define the sequence $\left\{v_{n}\right\}$ as follows: find $m(n)$ as the smallest positive integer $m$ satisfying

$$
g\left(\left(1-\gamma^{m}\right) x_{n}+\gamma^{m} y_{n}, x_{n}\right)-g\left(\left(1-\gamma^{m}\right) x_{n}+\gamma^{m} y_{n}, y_{n}\right) \geq \frac{\rho}{2 \lambda_{n}}\left\|x_{n}-y_{n}\right\|^{2} .
$$


In particular, let $z_{n}:=\left(1-\gamma^{m(n)}\right) x_{n}+\gamma^{m(n)} y_{n}$. Choose $t_{n} \in \partial g\left(z_{n}, \cdot\right)\left(x_{n}\right)$ and $\sigma_{n}:=g\left(z_{n}, x_{n}\right) /$ $\left\|t_{n}\right\|^{2}$. Next,

$$
v_{n}:=P_{C}\left(x_{n}-\xi_{n} \sigma_{n} t_{n}\right)
$$

If $\lim _{n \rightarrow \infty}\left(\left\|v_{n}-p\right\|-\left\|x_{n}-p\right\|\right)=0$ for some $p \in \Omega$, then

(1) $\lim _{n \rightarrow \infty} \sigma_{n}\left\|t_{n}\right\|=0$,

(2) $\lim _{n \rightarrow \infty}\left\|x_{n}-y_{n}\right\|=0$.

Proof Assume that $\lim _{n \rightarrow \infty}\left(\left\|v_{n}-p\right\|-\left\|x_{n}-p\right\|\right)=0$ for some $p \in \Omega$. By Lemma 20 we have

$$
\left\|v_{n}-p\right\|^{2} \leq\left\|x_{n}-p\right\|^{2}-\xi_{n}\left(2-\xi_{n}\right) \sigma_{n}^{2}\left\|t_{n}\right\|^{2}
$$

Since $\xi_{n} \in[\underline{\xi}, \bar{\xi}] \subset(0,2)$ and $\left\{x_{n}\right\}$ is bounded, we have that $\left\{v_{n}\right\}$ is bounded, and hence

$$
0 \leq \xi_{n}\left(2-\xi_{n}\right) \sigma_{n}^{2}\left\|t_{n}\right\|^{2} \leq\left\|x_{n}-p\right\|^{2}-\left\|v_{n}-p\right\|^{2} \rightarrow 0
$$

This implies that $\lim _{n \rightarrow \infty} \sigma_{n}\left\|t_{n}\right\|=0$. It follows from Lemma 22 that $\left\{y_{n}\right\}$ is bounded and so is $\left\{z_{n}\right\}$. So $\left\{t_{n}\right\}$ is bounded by Lemma 21. Since $g\left(z_{n}, \cdot\right)$ is convex, we have $0=g\left(z_{n}, z_{n}\right) \leq$ $\left(1-\gamma^{m(n)}\right) g\left(z_{n}, x_{n}\right)+\gamma^{m(n)} g\left(z_{n}, y_{n}\right)$, and hence $\gamma^{m(n)}\left(g\left(z_{n}, x_{n}\right)-g\left(z_{n}, y_{n}\right)\right) \leq g\left(z_{n}, x_{n}\right)$. Thus

$$
\frac{\gamma^{m(n)} \rho}{2 \lambda_{n}}\left\|x_{n}-y_{n}\right\|^{2} \leq \gamma^{m(n)}\left(g\left(z_{n}, x_{n}\right)-g\left(z_{n}, y_{n}\right)\right) \leq g\left(z_{n}, x_{n}\right)=\sigma_{n}\left\|t_{n}\right\|^{2} \rightarrow 0 .
$$

Since $\lambda_{n} \leq \bar{\lambda}$, we obtain

$$
\lim _{n \rightarrow \infty} \gamma^{m(n)}\left\|x_{n}-y_{n}\right\|^{2}=0
$$

We will prove that $\lim _{n \rightarrow \infty}\left\|x_{n}-y_{n}\right\|=0$ by contradiction. Suppose that there are $\varepsilon>0$ and a strictly increasing sequence $\left\{n_{k}\right\}$ such that $\left\|x_{n_{k}}-y_{n_{k}}\right\| \geq \epsilon$ for all $k \geq 1$.

Case 1: $\lim \sup _{k \rightarrow \infty} \gamma^{m\left(n_{k}\right)}>0$. This implies that

$$
\limsup _{k \rightarrow \infty} \gamma^{m\left(n_{k}\right)}\left\|x_{n_{k}}-y_{n_{k}}\right\|^{2}>0
$$

which is a contradiction.

Case 2: $\limsup _{k \rightarrow \infty} \gamma^{m\left(n_{k}\right)}=0$. There is a further subsequence $\left\{n_{k_{l}}\right\}$ of $\left\{n_{k}\right\}$ such that $\lim _{l \rightarrow \infty} \gamma^{m\left(n_{k_{l}}\right)}=0$ and $x_{n_{k_{l}}} \rightarrow x$ and $y_{n_{k_{l}}} \rightarrow y$ for some $x, y \in \mathcal{H}$. We write $\bar{z}_{n}:=$ $\left(1-\gamma^{m(n)-1}\right) x_{n}+\gamma^{m(n)-1} y_{n}$. In particular, we have

$$
g\left(\bar{z}_{n_{k_{l}}}, x_{n_{k_{l}}}\right)-g\left(\bar{z}_{n_{k_{l}}}, y_{n_{k_{l}}}\right)<\frac{\rho}{2 \lambda_{n_{k_{l}}}}\left\|x_{n_{k_{l}}}-y_{n_{k_{l}}}\right\|^{2}
$$

It follows from the definition of $y_{n}$ and $x_{n} \in C$ that

$$
\left\|x_{n}-y_{n}\right\|^{2} \leq-\lambda_{n} g\left(x_{n}, y_{n}\right)
$$


This implies that

$$
\left(1-\frac{\rho}{2}\right)\left\|x_{n_{k_{l}}}-y_{n_{k_{l}}}\right\|^{2}<\lambda_{n_{k_{l}}}\left(g\left(\bar{z}_{n_{k_{l}}}, y_{n_{k_{l}}}\right)-g\left(\bar{z}_{n_{k_{l}}}, x_{n_{k_{l}}}\right)-g\left(x_{n_{k_{l}}}, y_{n_{k_{l}}}\right)\right) \text {. }
$$

Since $\lim _{l \rightarrow \infty} \gamma^{m\left(n_{k_{l}}\right)}=0$ and $\gamma \in(0,1)$, it follows that $\lim _{l \rightarrow \infty} \gamma^{m\left(n_{k_{l}}\right)-1}=0$. In particular, $\bar{z}_{n_{k_{l}}} \rightarrow x$. It follows from condition (A4) for $g$ and $\limsup _{n \rightarrow \infty} \lambda_{n} \leq \bar{\lambda}$ that

$$
\lim _{l \rightarrow \infty}\left\|x_{n_{k_{l}}}-y_{n_{k_{l}}}\right\|=0
$$

which is a contradiction.

As in the proof of Lemma 23 with $\xi_{n}:=1$ for all $n \geq 1$, we obtain an analog of the preceding lemma with $v_{n}:=P_{C \cap D_{n}}\left(x_{n}\right)$.

Lemma 24 Let $\left\{x_{n}\right\}$ be a bounded sequence in C. Let $\rho \in(0,2)$ and $\gamma \in(0,1)$, and let $\left\{\lambda_{n}\right\} \subset(0, \bar{\lambda}] \subset(0, \infty)$. Assume that $g: \mathcal{H} \times \mathcal{H} \rightarrow \mathbb{R}$ satisfies (A1), (A4), and (A5). Define the sequence $\left\{y_{n}\right\}$ by

$$
y_{n}:=\operatorname{argmin}\left\{\lambda_{n} g\left(x_{n}, w\right)+\frac{1}{2}\left\|w-x_{n}\right\|^{2}: w \in C\right\} .
$$

Assume that $y_{n} \neq x_{n}$ for all $n \geq 1$. Define the sequence $\left\{v_{n}\right\}$ as follows: find $m(n)$ as the smallest positive integer $m$ satisfying

$$
g\left(\left(1-\gamma^{m}\right) x_{n}+\gamma^{m} y_{n}, x_{n}\right)-g\left(\left(1-\gamma^{m}\right) x_{n}+\gamma^{m} y_{n}, y_{n}\right) \geq \frac{\rho}{2 \lambda_{n}}\left\|x_{n}-y_{n}\right\|^{2} .
$$

In particular, let $z_{n}:=\left(1-\gamma^{m(n)}\right) x_{n}+\gamma^{m(n)} y_{n}$. Choose $t_{n} \in \partial g\left(z_{n}, \cdot\right)\left(x_{n}\right)$ and $\sigma_{n}:=g\left(z_{n}, x_{n}\right) /$ $\left\|t_{n}\right\|^{2}$. Next,

$$
v_{n}:=P_{C \cap D_{n}}\left(x_{n}\right),
$$

where $D_{n}:=\left\{w \in \mathcal{H}:\left\langle t_{n}, x_{n}-w\right\rangle \geq g\left(z_{n}, x_{n}\right)\right\}$. If $\lim _{n \rightarrow \infty}\left(\left\|v_{n}-p\right\|-\left\|x_{n}-p\right\|\right)=0$ for some $p \in \Omega$, then $\lim _{n \rightarrow \infty} \sigma_{n}\left\|t_{n}\right\|=\lim _{n \rightarrow \infty}\left\|x_{n}-y_{n}\right\|=0$.

Theorem 25 Let $\left\{x_{n}\right\}$ be a sequence generated by Algorithm 2 satisfying Assumption 2. Then $\left\{x_{n}\right\}$ converges strongly to $x^{*}=P_{\Omega} h\left(x^{*}\right)$.

Proof Let $p \in \Omega$. We know that

$$
\left\|P_{C}\left(\alpha_{n} h\left(v_{n}\right)+\left(1-\alpha_{n}\right) v_{n}\right)-p\right\| \leq\left\|\left(\alpha_{n} h\left(v_{n}\right)+\left(1-\alpha_{n}\right) v_{n}\right)-p\right\|
$$

for all $n \geq 1$. By Lemma 20 we have

$$
\left\|v_{n}-p\right\|^{2} \leq\left\|x_{n}-p\right\|^{2}-\xi_{n}\left(2-\xi_{n}\right)\left(\sigma_{n}\left\|t_{n}\right\|\right)^{2},
$$

where $\sigma_{n}:=g\left(z_{n}, x_{n}\right) /\left\|t_{n}\right\|^{2}$ if $y_{n} \neq x_{n}$ and $\sigma_{n}=0$ otherwise. Since $\xi_{n} \in(0,2)$, we get $\left\|v_{n}-p\right\| \leq\left\|x_{n}-p\right\| \quad$ for all $n \geq 1$. Hence $\left\{x_{n}\right\}$ is a Halpern sequence with respect to $\Omega$ 
associated with $\left\{\alpha_{n}\right\},\{0\},\left\{v_{n}\right\},\left\{v_{n}\right\},\left\{w_{n}\right\}$, and $h$, where $w_{n}:=P_{C}\left(\alpha_{n} h\left(v_{n}\right)+\left(1-\alpha_{n}\right) v_{n}\right)$. Moreover, we have that $\left\{x_{n}\right\}$ is bounded, and so is $\left\{v_{n}\right\}$ by Remark 3 .

Next, we prove that $\omega_{w}\left\{v_{n_{k}}\right\} \subset \Omega$ whenever $\left\{x_{n_{k}}\right\}$ is a subsequence of $\left\{x_{n}\right\}$ such that $\lim _{k \rightarrow \infty}\left(\left\|v_{n_{k}}-p\right\|-\left\|x_{n_{k}}-p\right\|\right)=0$ for some $p \in \Omega$. To see this, let $\left\{x_{n_{k}}\right\}$ and $\left\{v_{n_{k}}\right\}$ be such subsequences. Without loss of generality, we assume that $y_{n_{k}} \neq x_{n_{k}}$ for all $k \geq 1$. Note that $\left\{x_{n_{k}}\right\}$ is bounded by Remark 3. From Lemma 23 we obtain $\lim _{k \rightarrow \infty}\left\|x_{n_{k}}-y_{n_{k}}\right\|=0$. By Lemma 8 we have

$$
\omega_{w}\left\{x_{n_{k}}\right\} \subset \Omega
$$

Moreover, we have $\lim _{k \rightarrow \infty} \sigma_{n_{k}}\left\|t_{n_{k}}\right\|=0$ by Lemma 23. Since $\left\{x_{n_{k}}\right\} \subset C$, we obtain $\| v_{n_{k}}-$ $x_{n_{k}}\|=\| P_{C}\left(x_{n_{k}}-\xi_{n_{k}} \sigma_{n_{k}} t_{n_{k}}\right)-P_{C} x_{n_{k}}\left\|\leq \xi_{n_{k}} \sigma_{n_{k}}\right\| t_{n_{k}} \| \rightarrow 0$. Thus $\omega_{w}\left\{v_{n_{k}}\right\}=\omega_{w}\left\{x_{n_{k}}\right\} \subset \Omega$. Hence $x_{n} \rightarrow x^{*}=P_{\Omega} h\left(x^{*}\right)$ by Theorem 4 .

We now apply Theorem 25 to recover [10, Theorem 4.4].

Theorem 26 Let $C$ be a nonempty closed convex subset of $\mathcal{H}$, and let $f, g: \mathcal{H} \times \mathcal{H} \rightarrow \mathbb{R}$ be two bifunctions such that $f$ satisfies (A2), (A5), and (A7) and g satisfies (A1), (A4), and (A5). Assume that

(i) $0<\mu<2 \beta / L^{2}, \rho \in(0,2)$, and $\gamma \in(0,1)$;

(ii) A sequence $\left\{\alpha_{n}\right\} \subset(0,1)$ is such that $\lim _{n \rightarrow \infty} \alpha_{n}=0$ and $\sum_{n=1}^{\infty} \alpha_{n}=\infty$;

(iii) $\lambda_{n} \in[\underline{\lambda}, \bar{\lambda}] \subset(0, \infty)$ and $\xi_{n} \in[\underline{\xi}, \bar{\xi}] \subset(0,2)$ for all $n \geq 1$.

Let $\left\{x_{n}\right\} \subset C$ be the sequence defined as follows: $x_{1} \in C$ is arbitrarily chosen, and

$$
y_{n}:=\operatorname{argmin}\left\{\lambda_{n} g\left(x_{n}, y\right)+\frac{1}{2}\left\|y-x_{n}\right\|^{2}: y \in C\right\} .
$$

If $y_{n}=x_{n}$, then $v_{n}:=x_{n}$. If $y_{n} \neq x_{n}$, then (Armijo line search rule) find $m(n)$ as the smallest positive integer $m$ satisfying

$$
g\left(\left(1-\gamma^{m}\right) x_{n}+\gamma^{m} y_{n}, x_{n}\right)-g\left(\left(1-\gamma^{m}\right) x_{n}+\gamma^{m} y_{n}, y_{n}\right) \geq \frac{\rho}{2 \lambda_{n}}\left\|x_{n}-y_{n}\right\|^{2} .
$$

In particular, let $z_{n}:=\left(1-\gamma^{m(n)}\right) x_{n}+\gamma^{m(n)} y_{n}$. Choose $t_{n} \in \partial g\left(z_{n}, \cdot\right)\left(x_{n}\right)$ and $\sigma_{n}:=g\left(z_{n}, x_{n}\right) /$ $\left\|t_{n}\right\|^{2}$. Next,

$$
\begin{aligned}
& v_{n}:=P_{C}\left(x_{n}-\xi_{n} \sigma_{n} t_{n}\right) ; \\
& u_{n}:=S_{f}\left(v_{n}\right) ; \\
& x_{n+1}:=P_{C}\left(v_{n}-\alpha_{n} \mu u_{n}\right) \quad \text { for } n \geq 1 .
\end{aligned}
$$

Then $\left\{x_{n}\right\}$ converges strongly to $x^{*}=P_{\Omega}\left(x^{*}-\mu S_{f}\left(x^{*}\right)\right)$.

Proof We know that $I-\mu S_{f}$ is a contraction by Lemma 11. Note that

$$
x_{n+1}=P_{C}\left(v_{n}-\alpha_{n} \mu S_{f}\left(v_{n}\right)\right)=P_{C}\left(\alpha_{n}\left(I-\mu S_{f}\right) v_{n}+\left(1-\alpha_{n}\right) v_{n}\right) .
$$

By Theorem 25 we have that $\left\{x_{n}\right\}$ converges strongly to $x^{*}=P_{\Omega}\left(x^{*}-\mu S_{f}\left(x^{*}\right)\right)$. 
Remark 27 Theorem 26 improves [10, Theorem 4.4] in the following ways.

(a) We exclude conditions (A6) and (A8) for the bifunction $f$ and condition (A6) for $g$ as were the cases in [10, Theorem 4.4].

(b) We can replace the condition $\sum_{n=1}^{\infty} \alpha_{n}^{2}<\infty$ by the weaker condition $\lim _{n \rightarrow \infty} \alpha_{n}=0$. Moreover, the choice $\alpha_{n}:=1 / \sqrt{n}$ is applicable in our result, but it is beyond the scope of [10, Theorem 4.4].

Next, we construct Algorithm 2a, which is the same as Algorithm 2, except that $v_{n}:=$ $P_{C}\left(x_{n}-\xi_{n} \sigma_{n} t_{n}\right)$ is replaced by $v_{n}:=P_{C \cap D_{n}}\left(x_{n}\right)$ where $D_{n}:=\left\{w \in \mathcal{H}:\left\langle t_{n}, x_{n}-w\right\rangle \geq g\left(z_{n}, x_{n}\right)\right\}$. We can conclude the same conclusion as follows.

Theorem 28 Let $\left\{x_{n}\right\}$ be a sequence generated by Algorithm 2 a satisfying Assumption 2. Then $\left\{x_{n}\right\}$ converges strongly to $x^{*}=P_{\Omega} h\left(x^{*}\right)$.

Proof First, since $t_{n} \in \partial g\left(z_{n}, \cdot\right)\left(x_{n}\right)$, we get $\left\langle t_{n}, x_{n}-z_{n}\right\rangle \geq g\left(z_{n}, x_{n}\right)$. Hence $z_{n} \in C \cap D_{n}$. It follows that

$$
\begin{aligned}
\left\|v_{n}-x_{n}\right\| & =\left\|P_{C \cap D_{n}}\left(x_{n}\right)-x_{n}\right\| \\
& =\left\|P_{C \cap D_{n}}\left(x_{n}\right)-P_{C \cap D_{n}}\left(z_{n}\right)+z_{n}-x_{n}\right\| \\
& \leq\left\|P_{C \cap D_{n}}\left(x_{n}\right)-P_{C \cap D_{n}}\left(z_{n}\right)\right\|+\left\|z_{n}-x_{n}\right\| \\
& \leq 2\left\|x_{n}-z_{n}\right\|=2 \gamma^{m(n)}\left\|x_{n}-y_{n}\right\| .
\end{aligned}
$$

We now follow the proof of Theorem 25 and prove that $\omega_{w}\left\{v_{n_{k}}\right\} \subset \Omega$ whenever $\left\{x_{n_{k}}\right\}$ is a subsequence if $\left\{x_{n}\right\}$ such that $\lim _{k \rightarrow \infty}\left(\left\|v_{n_{k}}-p\right\|-\left\|x_{n_{k}}-p\right\|\right)=0$ for some $p \in \Omega$. To see this, let $\left\{x_{n_{k}}\right\}$ and $\left\{v_{n_{k}}\right\}$ be such subsequences. Without loss of generality, we assume that $y_{n_{k}} \neq x_{n_{k}}$ for all $k \geq 1$. Note that $\left\{x_{n_{k}}\right\}$ is bounded by Remark 3. From Lemma 24 we obtain $\lim _{k \rightarrow \infty}\left\|x_{n_{k}}-y_{n_{k}}\right\|=0$. By Lemma 8 we have

$$
\omega_{w}\left\{x_{n_{k}}\right\} \subset \Omega
$$

Note that $\lim _{k \rightarrow \infty} \gamma^{m\left(n_{k}\right)}\left\|x_{n_{k}}-y_{n_{k}}\right\|=0$. In particular, $\lim _{k \rightarrow \infty}\left\|v_{n_{k}}-x_{n_{k}}\right\|=0$, and hence $\omega_{w}\left\{v_{n_{k}}\right\} \subset \Omega$. This completes the proof.

We now apply Theorem 28 to Theorem 4.4 of [9] where $S:=I$.

Theorem 29 Let $C$ be a nonempty closed convex subset of $\mathcal{H}$, and let $g: \mathcal{H} \times \mathcal{H} \rightarrow \mathbb{R}$ be a bifunction satisfying (A1), (A4), and (A5). Assume that $F: \mathcal{H} \rightarrow \mathcal{H}$ is $\gamma$-Lipschitz continuous and $\beta$-strongly monotone. Assume that

(i) $\rho \in(0,2)$ and $\gamma \in(0,1)$;

(ii) A sequence $\left\{\alpha_{n}\right\} \subset(0,1)$ is such that $\lim _{n \rightarrow \infty} \alpha_{n}=0$ and $\sum_{n=1}^{\infty} \alpha_{n}=\infty$;

(iii) $\left\{\lambda_{n}\right\} \subset[\underline{\lambda}, \bar{\lambda}] \subset(0, \infty)$ for all $n \geq 1$.

Let $\left\{x_{n}\right\} \subset C$ be the sequence defined as follows: $x_{1} \in C$ is arbitrarily chosen, and

$$
y_{n}:=\operatorname{argmin}\left\{\lambda_{n} g\left(x_{n}, y\right)+\frac{1}{2}\left\|y-x_{n}\right\|^{2}: y \in C\right\}
$$


If $y_{n}=x_{n}$, then $v_{n}:=x_{n}$. If $y_{n} \neq x_{n}$, then (Armijo line search rule) find $m(n)$ as the smallest positive integer $m$ satisfying

$$
g\left(\left(1-\gamma^{m}\right) x_{n}+\gamma^{m} y_{n}, x_{n}\right)-g\left(\left(1-\gamma^{m}\right) x_{n}+\gamma^{m} y_{n}, y_{n}\right) \geq \frac{\rho}{2 \lambda_{n}}\left\|x_{n}-y_{n}\right\|^{2} .
$$

In particular, let $z_{n}:=\left(1-\gamma^{m(n)}\right) x_{n}+\gamma^{m(n)} y_{n}$. Choose $t_{n} \in \partial g\left(z_{n}, \cdot\right)\left(x_{n}\right)$. Next,

$$
\begin{aligned}
& D_{n}:=\left\{x \in \mathcal{H}:\left\langle t_{n}, x_{n}-x\right\rangle \geq g\left(z_{n}, x_{n}\right)\right\} ; \\
& v_{n}:=P_{C \cap D_{n}}\left(x_{n}\right) ; \\
& x_{n+1}:=P_{C}\left(v_{n}-\alpha_{n} F v_{n}\right) \quad \text { for } n \geq 1 .
\end{aligned}
$$

Then $\left\{x_{n}\right\}$ converges strongly to $x^{*}=P_{\Omega}\left(x^{*}-F x^{*}\right)$.

Proof Note that $I-\mu F$ is a contraction whenever $0<\mu<2 \beta / \gamma^{2}$. We can rewrite

$$
x_{n+1}=P_{C}\left(\frac{\alpha_{n}}{\mu}(I-\mu F) v_{n}+\left(1-\frac{\alpha_{n}}{\mu}\right) v_{n}\right) .
$$

From Theorem 28 with $h:=I-\mu F$ we conclude that $\left\{x_{n}\right\}$ converges strongly to $x^{*}=P_{\Omega}\left(x^{*}-\right.$ $\left.\mu F x^{*}\right)=P_{\Omega}\left(x^{*}-F x^{*}\right)$. The latter equality holds because of the property of the projection $P_{\Omega}$.

Remark 30 Theorem 29 improves [9, Theorem 4.4] in the following ways.

- The condition $\sum_{n=1}^{\infty} \alpha_{n}^{2}<\infty$ is replaced by the weaker condition $\lim _{n \rightarrow \infty} \alpha_{n}=0$.

- The condition $0<\underline{\lambda} \leq \lambda_{n} \leq 1$ for all $n \geq 1$ is replaced by the weaker condition $\lambda_{n} \in[\underline{\lambda}, \bar{\lambda}] \subset(0, \infty)$ for all $n \geq 1$.

\section{Conclusion}

We apply the notion of a Halpern-type sequence introduced by the authors [6] for the problem of finding a solution of bilevel equilibrium problems. We can cover two recent results of Yuying et al. [10], where the first one uses the algorithm of Halpern-Korpelevič type, and the second one uses the extragradient-like algorithm with line search technique. The convergence results are established under weaker assumptions. The method used in this paper is simple and excludes some restrictions as were the cases in many results in the literature.

\section{Acknowledgements}

The authors thank the referees for their comments and suggestion on the manuscript. The first author is supported by the Post-Doctoral Training Program from Khon Kaen University, Thailand (Grant No. PD2563-02-11).

Funding

This work has received scholarship under the Post-Doctoral Training Program from Khon Kaen University, Thailand.

\section{Abbreviations}

Not applicable.

Availability of data and materials

Not applicable.

Ethics approval and consent to participate 
Competing interests

The authors declare that they have no competing interests.

\section{Consent for publication}

Not applicable.

\section{Authors' contributions}

The authors have equally made contributions. Both authors read and approved the final manuscript.

Authors' information

Not applicable.

\section{Author details}

'Department of Applied Mathematics and Statistics, Faculty of Sciences and Liberal Arts, Rajamangala University of Technology Isan, Nakhon Ratchasima, Thailand. ²Department of Mathematics, Faculty of Science, Khon Kaen University, Khon Kaen, Thailand.

\section{Publisher's Note}

Springer Nature remains neutral with regard to jurisdictional claims in published maps and institutional affiliations.

Received: 1 July 2021 Accepted: 18 September 2021 Published online: 28 September 2021

\section{References}

1. Anh, P.N.: A hybrid extragradient method extended to fixed point problems and equilibrium problems. Optimization 62, 271-283 (2013)

2. Bauschke, H.H., Combettes, P.L.: Convex Analysis and Monotone Operator Theory in Hilbert Spaces, 2nd edn. CMS Books in Mathematics. Springer, Cham (2017)

3. Blum, E., Oettli, W.: From optimization and variational inequality to equilibrium problems. Math. Stud. 63, 123-145 (1994)

4. Dinh, B.V., Kim, D.S.: Extragradient algorithms for equilibrium problems and symmetric generalized hybrid mappings. Optim. Lett. 11, 537-553 (2017)

5. lusem, A.N.: On the maximal monotonicity of diagonal subdifferential operators. J. Convex Anal. 18, 489-503 (2011)

6. Jaipranop, C., Saejung, S.: On Halpern-type sequences with applications in variational inequality problems. Optimization (2020). https://doi.org/10.1080/02331934.2020.1812065

7. Saejung, S.: Fixed Point Algorithms and Related Topics. Yokohama Publishers (2017)

8. Vuong, P.T., Strodiot, J.J., Nguyen, V.H.: Extragradient methods and linesearch algorithms for solving Ky Fan inequalities and fixed point problems. J. Optim. Theory Appl. 155, 605-627 (2012)

9. Vuong, P.T., Strodiot, J.J., Nguyen, V.H.: On extragradient-viscosity methods for solving equilibrium and fixed point problems in a Hilbert space. Optimization 64, 429-451 (2015)

10. Yuying, T., Dinh, B.V., Kim, D.S., Plubtieng, S.: Extragradient subgradient methods for solving bilevel equilibrium problems. J. Inequal. Appl. 2018, Article ID 327 (2018)

\section{Submit your manuscript to a SpringerOpen ${ }^{\circ}$ journal and benefit from:}

- Convenient online submission

- Rigorous peer review

- Open access: articles freely available online

- High visibility within the field

- Retaining the copyright to your article 